University of Nebraska - Lincoln

DigitalCommons@University of Nebraska - Lincoln

Faculty Publications, Department of Psychology

Psychology, Department of

2012

\title{
Implicit and Explicit Alcohol-Related Motivations among College Binge Drinkers
}

\author{
Laura C. Herschl \\ University of Nebraska-Lincoln \\ Dennis E. McChargue \\ University of Nebraska-Lincoln, dmcchargue2@unl.edu \\ James MacKillop \\ University of Georgia and Brown University, jmackill@mcmaster.ca \\ Scott F. Stoltenberg \\ University of Nebraska-Lincoln, sstoltenberg2@unl.edu \\ Krista B. Highland \\ Univeristy of Nebraska-Lincoln
}

Follow this and additional works at: https://digitalcommons.unl.edu/psychfacpub

Part of the Psychology Commons

Herschl, Laura C.; McChargue, Dennis E.; MacKillop, James; Stoltenberg, Scott F.; and Highland, Krista B., "Implicit and Explicit Alcohol-Related Motivations among College Binge Drinkers" (2012). Faculty Publications, Department of Psychology. 1022.

https://digitalcommons.unl.edu/psychfacpub/1022

This Article is brought to you for free and open access by the Psychology, Department of at DigitalCommons@University of Nebraska - Lincoln. It has been accepted for inclusion in Faculty Publications, Department of Psychology by an authorized administrator of DigitalCommons@University of Nebraska - Lincoln. 


\title{
Implicit and Explicit Alcohol-Related Motivations among College Binge Drinkers
}

\author{
Laura C. Herschl, ${ }^{1}$ Dennis E. McChargue, ${ }^{1}$ James MacKillop, ${ }^{2}$ \\ Scott F. Stoltenberg, ${ }^{1}$ and Krista B. Highland ${ }^{1}$
}

1. Department of Psychology, 238 Burnett Hall, University of Nebraska-Lincoln, Lincoln, Nebraska, USA

2. Department of Psychology, Psychology Building, University of Georgia, Athens, Georgia, USA, and Center for Alcohol and Addiction Studies, Brown University, Providence, Rhode Island, USA

Corresponding author - D. E. McChargue, email dmcchargue2@unlnotes.unl.edu

\begin{abstract}
Rationale: Positive alcohol outcome expectancies and behavioral economic indices of alcohol consumption are related to binge drinking among college students and may reflect explicit and implicit motivations that are differentially associated with this behavior. Objectives: The present study hypothesized that implicit (alcohol purchase task) and explicit (positive expectancy for alcohol's effects) motivations for drinking would not be correlated. It was also hypothesized that greater implicit and explicit motivations would predict alcohol-related risk. Methods: Participants were 297 college student binge drinkers (54\% female; 88\% European-American; Alcohol Use Disorders Identification Test: $M=9.53, \mathrm{SD}=5.04)$. Three indices from the alcohol purchase task (APT) were modeled as a latent implicit alcohol-related motivations variable. Explicit alcohol-related motivations were measured using a global positive expectancy subscale from the Comprehensive Effects of Alcohol Questionnaire. Alcohol Use Disorders Identification Test total, Rutgers Alcohol Problem Index total, and age of drinking onset were modeled as a latent alcohol-related risk variable. Structural equation modeling was used to examine associations amongst implicit motivations, explicit motivations, and alcohol-related risk. Results: Implicit and explicit motivations were not correlated. Partially consistent with the second hypothesis, greater implicit motivations were associated with greater alcoholrelated risk. Relations between explicit motivations and alcohol-related risk were marginally significant. Conclusions: Implicit and explicit drinking motivations are differentially associated with problem
\end{abstract}


drinking behaviors. Future research should examine the underlying neurobiological mechanisms associated with these factors.

Keywords: college students, binge drinking, alcohol expectancies, behavioral economics, implicit motivation, explicit motivation, structural equation modeling

\section{Introduction}

Binge drinking (a pattern of alcohol use that results in rapid intoxication) is a prevalent public health issue in the United States, with nearly half of all college students consuming an amount of alcohol at or above the threshold for binging within a 2-week period (Wechsler et al. 2002). Negative consequences of such consumption include, but are not limited to, emotional instability (Weinberger and Bartholomew 1996), risky sexual behavior (Turrisi et al. 2000), suicidal ideation (Schaffer et al. 2008), and legal problems (Perkins 2002). Moreover, binge drinking accounts for approximately 500,000 injuries and 1,700 deaths in students at ages 18-24 each year (Hingson et al. 2005). There is a wealth of knowledge on risk factors (e.g., paternal alcoholism, low level of response to alcohol, certain genetic polymorphisms, and temperament) (Enoch 2006; Knop et al. 2003; Ozkaragoz and Noble 2000; Schuckit 1998) and consequences associated with binge drinking. More recent literature, however, has begun to examine the influence of explicit and implicit motivations to drink alcohol (e.g., Wiers et al. 2002a, b, 2005). This focus has been driven by concerns that wellestablished explicit motivations, such as expectancies, may not capture the total variance of alcohol-related motivation. The purpose of the present study was to test the degree to which implicit and explicit alcohol-related motivations independently predict drinking outcomes.

For example, alcohol outcome expectancies have been strongly associated with a wide array of alcohol consumption patterns (Jones et al. 2001) and reflect explicit motivations for use (Reich et al. 2010). Expectancy theory posits that repeated beliefs linking a behavior and an outcome serve to shape decision making in a manner that increases that behavior (Smith and Goldman 1995). The theory is rooted in a social learning framework, such that alcohol expectancies are based on both directly observable behaviors (alcohol consumption) and indirectly observable cognitive processes (expectancies). Furthermore, expectancies result from both direct and indirect experiences with alcohol. This is best illustrated through findings indicating that children possess expectancies about alcohol long before they ever consume it themselves (Christiansen and Goldman 1983).

A body of research indicates a positive relationship between alcohol consumption and positive alcohol outcome expectancies and a negative relationship between alcohol consumption and negative alcohol outcome expectancies (Fromme and D'Amico 2000). However, positive expectancies consistently have a stronger relationship with drinking behavior (Leigh and Stacy 1993; Stacy 1997; Stacy et al. 1990). Greater positive outcome expectancies discriminate between problem and nonproblem drinkers (Brown 1985) and are associated with increased alcohol-related negative consequences (e.g., blackouts, hangovers, and driving under the influence) in college students (Turrisi et al. 2000). Furthermore, greater positive expectancies predict future drinking in nondrinking adolescents 
(Smith et al. 1995). Positive expectancies have also predicted the persistence of alcohol dependence symptoms longitudinally (Kilbey et al. 1998).

Implicit motivation to drink has primarily been measured using alcohol-related cognitions and attitudes (e.g., implicit association test and free association test). However, the use of behavioral economic indices of alcohol consumption provides another implicit alcohol measure that may better reflect the reinforcement derived from alcohol (Mackillop and Murphy 2007). Reinforcement from substances is implicit in nature, such that motivation for substance use, substance-seeking, and substance administration behavior often operates without extensive conscious awareness as addiction strengthens (Curtin et al. 2006; Everitt and Robbins 2005). This phenomenon stems from the notion that actions that are repeated and reinforced (i.e., overlearned), such as alcohol use, require less allocation of cognitive resources (Puttemans et al. 2005). Specifically, the alcohol purchase task (APT; Murphy and Mackillop 2006) is an ideal index of implicit drinking motivations because it captures the multidimensionality of motivation for alcohol use through its five unique yet theoretically coherent indices. For example, Jacobs and Bickel (1999) examined demand indices from a hypothetical purchase task for cigarettes and heroin in opioid-dependent outpatients. Results indicated greater intensity of demand for cigarettes (i.e., number of cigarettes smoked when free); however, demand for heroin was less elastic (i.e., less sensitive to increasing price). In college students, the APT is related to current drinking (e.g., drinks/week, heavy drinking episodes/week, Rutgers Alcohol Problem Index (RAPI) scores) (Murphy and MacKillop 2006) and has been found to be predictive of treatment response and binge drinking episodes across time (MacKillop and Murphy 2007).

Meta-analysis data suggest that implicit and explicit drinking motivations are weakly related to each other and contribute to unique components of drinking behavior (Reich et al. 2010). More specifically, Wiers et al. (2002b) examined the differences between implicit and explicit alcohol-related cognitions (including expectancies) among college students. They found that while both light and heavy drinkers showed equivalent negative implicit associations with alcohol, heavy drinkers exhibited stronger positive explicit expectancies compared with light drinkers. Taken together, findings generally support the notion that explicit and implicit indices are differentially associated with alcohol use and reflect disparate motivational processes (Stacy 1997).

The present study attempted to replicate and expand upon prior research in two ways. First, we hypothesized that our measures of implicit and explicit motivations would also be weakly related. We also expected that both indices would uniquely predict greater alcohol related-risk. Second, historical measures have utilized alcohol-related cognitions and attitudes that are conceptualized as an implicit motivation to use. The present study expands upon prior research by adding a noncognitive measure of implicit motivation. Showing consistent findings will help support the notion that implicit motivation extends beyond alcohol-related cognitions and attitudes. 


\section{Materials and method}

\section{Participants and procedures}

College students $(N=297)$ from an undergraduate psychology subject pool volunteered to participate in the study. The criterion for inclusion was, for males, self-reporting typically drinking five or more drinks in a typical evening and for females, self-reporting typically drinking four or more drinks in a typical evening. Participants completed a questionnaire battery administered by the research investigator or an assistant. All participants gave written informed consent, and the university institutional review board approved this study. See Table 1 for a summary of sample characteristics.

\begin{tabular}{lc}
\hline \multicolumn{2}{l}{ Table 1. Sample characteristics } \\
\hline Variable & $M(\mathrm{SD})$ or $n(\%)$ \\
\hline Gender & $136(45.8 \%)$ \\
Male & $161(54.2 \%)$ \\
Female & \\
Ethnicity & $263(88.6 \%)$ \\
European-American & $9(3.0 \%)$ \\
African-American & $6(2.0 \%)$ \\
Latino/Hispanic & $8(2.7 \%)$ \\
Asian-American & $11(3.7 \%)$ \\
Other & $19.88(1.92)$ \\
Age & $16.14(1.70)$ \\
Age of onset & $9.53(5.04)$ \\
AUDIT total & $16.11(12.41)$ \\
RAPI total & \\
APT & $5.73(2.68)$ \\
Breakpoint & $7.55(4.24)$ \\
Intensity & $12.32(9.93)$ \\
Omax & $3.36(2.19)$ \\
Pmax & $.019578(.032021)$ \\
Elasticity & $57.63(8.70)$ \\
CEOA positive expectancy & \\
\hline
\end{tabular}

\section{Measures}

Demographic information

The demographic questionnaire included items regarding age, gender, race, year in school, grade point average, fraternity/sorority membership, employment status, emotional/mental health problems, medications, current living arrangement, family composition, family income, hometown population, age of onset of alcohol consumption, familial alcohol/drug problems, and legal problems. 


\section{Alcohol use disorders identification test}

The Alcohol Use Disorders Identification Test (AUDIT) (Saunders et al. 1993) was developed by the World Health Organization and consists of 10 Likert-type items used to assess harmful and hazardous alcohol use. The AUDIT assesses alcohol consumption (quantity and frequency), binge behavior, and alcohol-related consequences. Scores range from 0 to 40 , with a score of 8 or higher indicating the likelihood of harmful alcohol consumption. The AUDIT has shown good internal consistency (Fleming et al. 1991) and discriminant validity (Saunders et al. 1993).

\section{Rutger's alcohol problem index}

The Rutgers Alcohol Problem Index (RAPI) (White and Labouvie 1989) is used to assess problem drinking in adolescents and young adults. The RAPI includes 26 items related to problems experienced because of their alcohol use in the past 6 months, each of which is answered on a Likert-type scale ranging from 0 (never) to 4 (more than 10 times). The RAPI has shown good reliability, internal consistency, and validity with young adults (White and Labouvie 1989).

\section{Comprehensive effects of alcohol questionnaire}

The Comprehensive Effects of Alcohol Questionnaire (CEOA) (Fromme et al. 1993) includes 38 items to assess positive and negative alcohol-related expectancies (rated on 1-4 scale). The CEOA includes four positive expectancy domains (sociability, tension reduction, enhanced sexuality, and liquid courage) that comprised 20 items. These positive and negative expectancy subscales also yield global positive and negative expectancy scores. The CEOA has been shown to have adequate internal consistency, test-retest reliability, criterion validity, and factorial validity (Fromme et al. 1993).

\section{Alcohol purchase task}

The alcohol purchase task (APT) is a behavioral economic measure of the relative value of alcohol that assesses estimated alcohol consumption and the hypothetical financial expenditure across a range of drink prices. Participants are asked to respond to "How many drinks would you consume if they were ___ each," at the following 14 costs: zero (free), $\$ 0.25, \$ 0.50, \$ 1, \$ 1.50, \$ 2, \$ 2.50, \$ 3, \$ 4, \$ 5, \$ 6, \$ 7, \$ 8$, and $\$ 9$. Reinforcement from alcohol was determined in four ways as follows: breakpoint, intensity, maximum expenditure $\left(O_{\max }\right)$, and price associated with the maximum expenditure $\left(P_{\max }\right)$. Breakpoint was considered the first price at which alcohol consumption is zero. Individuals who did not have a breakpoint (i.e., would drink at the highest price) were assigned a breakpoint at the highest price (\$9). Intensity was the maximum level of consumption at the lowest price (\$0.00). $O_{\max }$ was defined as the greatest expenditure across prices (i.e., the most money an individual would spend on drinks in a given evening). $P_{\max }$ was the price associated with the maximum total expenditure (Murphy and MacKillop 2006). The APT has shown good reliability and validity (Murphy et al. 2009). Exponential demand curve modeling was also used to fit the alcohol consumption responses for each participant. This equation generates an estimate of elasticity of demand, which cannot be observed from raw data, and a goodness of fit measures $\left(R^{2}\right)$. In the equation, $\log _{10} Q=\log _{10} Q_{0}+k\left(e^{-\alpha} Q_{0} C-1\right)$, where $Q=$ 
consumption at a given price; $Q_{0}=$ maximum consumption (consumption at zero or minimal price); $k=\alpha$ constant across individuals that denotes the range of consumption values in $\log$ powers of ten, in this case, a constant of $1 ; C=$ the cost of the commodity (price); and $\alpha=$ the derived demand parameter reflecting a standardized rate of decline of consumption. Larger elasticity values reflect greater sensitivity to the increasing price. Demand curves were fit according to the Hursh and Silberberg (2008) guidelines using the calculator provided on the Institute for Behavioral Resources website (www.ibrinc.org/ibr/centers/ bec/BEC_demand.html).

\section{Data analysis plan}

First, one-way analysis of variance (ANOVA) was used to examine gender differences in implicit motivations (APT indices), explicit motivations (CEOA global positive expectancy), age of onset, AUDIT total, and RAPI total. This provided statistical support for controlling for gender in specific variables. Subsequently, Pearson's correlations were examined among age, implicit motivations (APT breakpoint, intensity, $O_{\max }, P_{\max }$, and elasticity), explicit motivations (CEOA global positive expectancy), age of onset, AUDIT total score, and RAPI total score. Correlations served to examine for any potential confounding variables as well as to test the relatedness of implicit and explicit alcohol-related motivations.

Confirmatory factor analysis (CFA) was used to derive the most parsimonious latent implicit motivations, explicit motivations, and alcohol-related risk variables. Structural equation modeling (SEM) was then employed to examine the associations among the latent implicit motivations variable, explicit motivations, and the latent alcohol-related risk variable. SEM was employed for a number of reasons. First, SEM develops a model of the relations among measured and latent variables in order to determine causal and associative relationships (Duncan et al. 2006; MacCallum and Austin 2000). Second, SEM tests for both linear and nonlinear effects on the criterion variables (Bollen 1986). The model was estimated using Mplus version 6.0 (Muthén and Muthén 1998-2010). Chi-square test of model fit, comparative fit index (CFI), and standardized root mean square residual (SRMR) were used as the primary criteria of model fit, with cutoff values of CFI > .95, and of SRMR $<.08$ indicative of good model fit (Bollen 1986). Several models were tested; however, only the most parsimonious model is presented.

\section{Results}

\section{Preliminary analyses}

ANOVAs were used to examine gender differences in implicit motivations (APT breakpoint, intensity, $O_{\max }, P_{\max }$, and elasticity), explicit motivations (CEOA global positive expectancy), age of onset, AUDIT total, and RAPI total. Results showed that males had higher APT intensity $[F(1,289)=57.63, \mathrm{SEM}=15.04, p<.001], O_{\max }[F(1,270)=11.73, \mathrm{SEM}=94.92$, $p=.001]$, and AUDIT total $[F(1,286)=9.69$, SEM $=24.71, p=.002]$ values than females. Gender was controlled for in $O_{\max }$, intensity, and AUDIT total due to significant differences between groups. This was accomplished by regressing gender on to $O_{\max }(\beta=-.08, p=\mathrm{ns})$, intensity $(\beta=.05, p=\mathrm{ns})$, and AUDIT $(\beta=-.01, p=\mathrm{ns})$, the method suggested by the Mplus 
authors, Muthén and Muthén (1998-2010). No other differences were observed between males and females. Examination of the exponential demand curve showed that it provided an acceptable fit for the data $\left(R^{2}=.66, \mathrm{SD}=.18\right)$.

Pearson's correlations were used to examine relationships among age, implicit motivations (APT breakpoint, intensity, $O_{\max }, P_{\max }$, and elasticity), explicit motivations (CEOA global positive expectancy), age of onset, AUDIT total score, and RAPI total score. Pearson's correlations showed that age of onset, AUDIT total, and RAPI total were significantly correlated with implicit motivations (with the exception of RAPI total and APT elasticity, $O_{\max }$, and $P_{\max }$; AUDIT total and $P_{\max }$ and elasticity; and age of onset and breakpoint and $P_{\max }$ ) and explicit motivations (with the exception of CEOA global positive expectancy and age of onset) in the expected directions. Please see Table 2 for the zero-order correlation matrix.

Table 2. Zero-order correlation matrix

\begin{tabular}{lcccccccccc}
\hline & 1 & 2 & 3 & 4 & 5 & 6 & 7 & 8 & 9 & 10 \\
\hline Age & - & .09 & -.02 & .00 & -.06 & .08 & $-.15^{*}$ & .01 & .07 & -.03 \\
Age of onset & - & - & $-.28^{* *}$ & $-.27^{* *}$ & -.17 & -.09 & $-.26^{* *}$ & $-.21^{* *}$ & .06 & $.17^{* *}$ \\
RAPI total & - & - & - & $.51^{* *}$ & $.26^{* *}$ & $.13^{*}$ & $.14^{*}$ & .10 & .00 & -.07 \\
AUDIT total & - & - & - & - & $.18^{* *}$ & $.16^{* *}$ & $.25^{* *}$ & $.16^{* *}$ & .10 & -.12 \\
CEOA pos & - & - & - & - & - & -.03 & $.07 \mathrm{~F}$ & -.05 & -.02 & .04 \\
Breakpoint & - & - & - & - & - & - & $.38^{* *}$ & $.64^{* *}$ & $.73^{* *}$ & $-.42^{* *}$ \\
Intensity & - & - & - & - & - & - & - & $.63^{* *}$ & $.18^{* *}$ & $-.38^{* *}$ \\
Omax & - & - & - & - & - & - & - & - & $.53^{* *}$ & $-.37^{* *}$ \\
$P_{\max }$ & - & - & - & - & - & - & - & - & - & $-.27^{* *}$ \\
Elasticity & - & - & - & - & - & - & - & - & - & - \\
\hline
\end{tabular}

Values not denoted with an asterisk, $p>.05$

${ }^{*} p<.05 ;{ }^{* *} p<.001$

\section{Primary analyses}

As illustrated in Table 2, zero-order correlations show significant relationships among implicit motivations (APT indices) but not between implicit and explicit motivations. Furthermore, implicit and explicit motivations were not correlated in the SEM model (Fig. 1). These data are inconsistent with the first hypothesis that implicit and explicit motivations would be weakly related. However, results support the notion that our constructs are independent from one another.

Confirmatory factor analysis (CFA) was used to test the adequacy of the latent implicit motivation measurement model. A single latent implicit motivation variable was posited to account for the pattern of the relationship across implicit motivation indices (APT breakpoint, $O_{\max }, P_{\max }$, intensity, and elasticity); however, this resulted in a poor-fitting model, maximum-likelihood $\chi^{2}(5)=22.73, p<.001, \mathrm{CFI}=.87$, and SRMR $=.05$. A four-index model (APT breakpoint, $O_{\max }, P_{\max }$, and intensity) was then tested and provided acceptable fit for the data, maximum-likelihood $\chi^{2}(2)=.441, p=.802$, CFI $>.99$, and SRMR $=.008$. APT breakpoint $(\beta=.71, p<.001)$, intensity $(\beta=.49, p<.001), O_{\max }(\beta=.27, p<.001)$, and $P_{\max }(\beta=.62$, $p<.001)$ all significantly contributed to the model. 
CFA was also used to test the adequacy of the latent explicit motivations model. Two models were tested. The first model posited that a single latent explicit motivation variable would account for the pattern of the relationship across the 20 positive expectancy items. However, this model resulted in a poor fit for the data, maximum-likelihood $\chi^{2}(170)=$ $452.26, p<.001, \mathrm{CFI}=.74$, and SRMR $=.07$. The second model posited that a single latent explicit motivation variable would account for the pattern of the relationship across the four positive expectancy subscales (sociability, tension reduction, enhanced sexuality, and liquid courage). This model provided acceptable fit for the data, maximum-likelihood $\chi^{2}(6)$ $=207.39, p<.001, \mathrm{CFI}=.95$, and SRMR $=.044$. Enhanced sexuality $(\beta=.43, p<.001)$, sociability $(\beta=.77, p<.001)$, tension reduction $(\beta=.35, p<.001)$, and liquid courage $(\beta=.77, p<.001)$ all significantly contributed to the model.

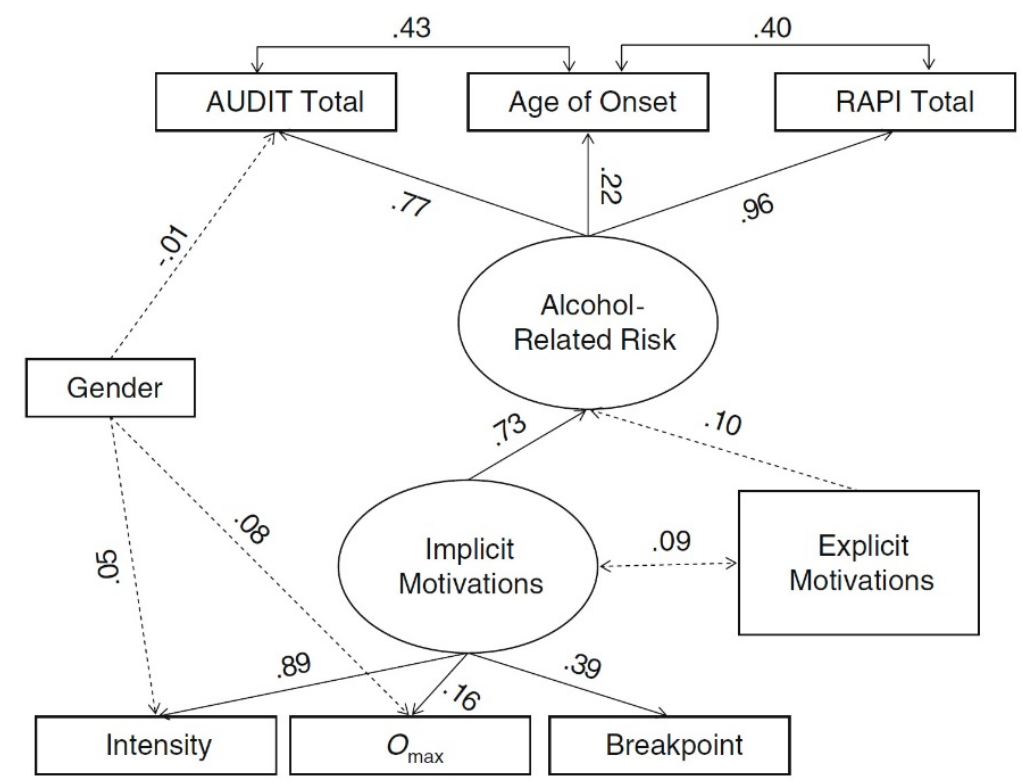

Figure 1. Structural equation model results. Solid lines indicate significant paths. Dashed lines indicate nonsignificant paths.

The adequacy of a latent alcohol-related risk model was then tested. The model posited that a single latent alcohol-related risk variable would account for the pattern of the relationship across AUDIT total, RAPI total, and age of drinking onset. Fit indices were acceptable, maximum-likelihood $\chi^{2}(0)<.001, p<.001, \mathrm{CFI}<.99$, and SRMR $<.001$. AUDIT total $(\beta=.99, p<.001)$, RAPI total $(\beta=.72, p<.001)$, and age of onset $(\beta=.47, p<.001)$ all significantly contributed to the latent alcohol-related risk variable.

SEM was used to examine the data from 297 college binge drinkers. The most parsimonious model included the observed explicit variable, removed $P_{\max }$ from the latent implicit motivation variable, and set the item loadings equal to one for AUDIT total, RAPI total, and age of onset in the alcoholrelated risk variable. The three-index implicit motivations model is supported by a previous research indicating that APT elasticity and $P_{\max }$ are less 
related to alcohol use (Murphy and MacKillop 2006), and the loadings were held equal to one in the alcohol-related risk latent variable due to a factor loading being greater than one for RAPI total when all loadings were freed. Overall fit of the model was acceptable, maximumlikelihood $\chi^{2}(14)=29.36, p=.009, \mathrm{CFI}=0.97$, and SRMR $=.043$. Consistent with the second hypothesis, greater levels of the implicit motivation variables predicted alcohol-related risk. Explicit motivations marginally $(p=.053)$ predicted alcohol-related risk. See Fig. 1 for the SEM results.

\section{Discussion}

The present study aimed to examine how implicit and explicit alcohol-related motivations are associated with problematic drinking behaviors. Results indicate that implicit (an alcohol purchase task) and explicit (positive expectancy for alcohol's effects) drinking motivations are independently associated with alcohol-related risk, which is consistent with prior studies (e.g., Reich et al. 2010). Our findings diverge from prior studies by showing that our measures were unrelated with one another, whereas meta-analytic data support a weak relationship (Reich et al. 2010). Furthermore, the present findings suggest that implicit motivations for alcohol use are a stronger predictor of alcohol-related risk than explicit motivations.

Our data add to the extant literature by testing a measure of implicit motivation that appeared to be an independent construct from the standard measure of explicit motivation. An advantage of our implicit measure of motivation is that it removes any measurement overlap with explicit motivation by removing the cognitive/attitudinal appraisal component of prior implicit assessments (e.g., Jajodia and Earleywine 2003; McCarthy and Thompsen 2006; Palafi and Wood 2001; Stacy 1997; Wiers et al. 2002b). This measurement overlap may have contributed to the relatedness of implicit and explicit motivation from other studies (Reich et al. 2010). Second, we modeled our implicit measure as a latent variable. Latent variables are viewed as a more accurate model of a construct because they allow multiple indices to differentially contribute to the factor rather than relying on one response pattern (Duncan et al. 2006). Taken together, our data provide some clarity on how explicit and implicit motivations act as independent predictors of alcohol-related outcomes.

It is noteworthy to mention that others (e.g., Wiers et al. 2002b) with similar findings to ours have posited that their data reflect Robinson and Berridge's $(1993,2001)$ incentivesensitization theory. Specifically, Wiers et al. (2002b) found that both heavy and light drinkers possessed negative implicit alcohol-related attitudes, which is consistent with the notion that incentive-sensitization "liking" decreases with repeated use. Studies attempting to assess incentive-sensitization among humans (Hobbs et al. 2005; Lambert et al. 2006; Ostafin et al. 2010; Willner et al. 2005) draw into question, however, the degree to which incentive-sensitization can be extrapolated from self-reported appraisals, particularly given that most studies did not find support for incentive-sensitization theory among atrisk and addicted populations (Hobbs et al. 2005; Ostafin et al. 2010; Willner et al. 2005). As such, a more parsimonious explanation of these findings is that they are measuring implicit and explicit motivations rather than incentive-sensitization. 
Despite this novel integration of behavioral economics and expectancy theory and their posited reflections of implicit (APT) and explicit (positive expectancy) alcohol-related motivations, limitations exist. First, we were unable to utilize a latent explicit motivation variable within the model, which may have influenced its marginally significant association with the alcohol-related risk latent variable. Second, age of drinking onset was negatively correlated with AUDIT total and RAPI total; however, it positively contributed to the latent alcohol-related risk variable. Some data suggest that less drinking experience may be associated with fewer strategies to prevent alcohol-related negative consequences (Lewis et al. 2009), which may explain its direction of influence within the context of the model. Third, our criterion for inclusion was self-reporting typically consuming alcohol amounts at or above the binge threshold on drinking occasions. Though AUDIT items 1 and 2 indicate that the majority of our sample binge drink on a (at least) monthly basis, future studies should utilize a timeline follow-back method for a more accurate assessment of drinking behavior. Fourth, we were not able to assess alcohol abuse/dependence within the sample, though it has been estimated that approximately $31 \%$ of students meet the criteria for abuse and $6 \%$ for dependence (Knight et al. 2002). Lastly, the ethnic composition of our sample indicates that these findings cannot be generalized to cultural groups outside of EuropeanAmericans.

Overall, findings indicate that problematic drinking behavior among college students is associated with both implicit and explicit alcohol-related motivations. Furthermore, explicit and implicit drinking motivations are differentially associated with drinking behavior. Future research would benefit from examining the underlying neurobiological mechanisms associated with these factors.

Acknowledgments - This study was supported by a Faculty Seed Grant from the University of NebraskaLincoln awarded to Dennis E. McChargue.

Conflicts of interest - The authors have no conflicts of interest.

\section{References}

Bollen KA (1986) Sample size and Bentler and Bonnett's nonnormed fit index. Psychometrika 51:375377. doi:10.1007/BF02294061

Brown SA (1985) Reinforcement expectancies and alcoholism treatment outcomes after a one-year follow-up. J Stud Alcohol 46 (4):304-308. Retrieved from http://www.jsad.com

Christiansen BA, Goldman MS (1983) Alcohol-related expectancies versus demographic/background variables in the prediction of adolescent drinking. J Consult Clin Psychol 51(2):249-257. doi:10.1037/0022-006X.51.2.249

Curtin JJ, McCarthy DE, Piper ME, Baker TB (2006) Implicit and explicit drug motivational processes: a model of boundary conditions. In: Wiers RW, Stacy AW (eds) Handbook of implicit cognition and addiction. Sage Publications, Inc, Thousand Oaks, pp 253-266

Duncan T, Duncan S, Strycker L (2006) An introduction to latent variable growth curve modeling: concepts, issues, and applications, 2nd ed. Lawrence Erlbaum Associates Publishers, Mahwah, NJ 
Enoch M (2006) Genetic and environmental influences on the development of alcoholism: resilience vs. risk. Ann N Y Acad Sci 1094:193-201. doi:10.1196/annals.1376.019

Everitt BJ, Robbins TW (2005) Neural systems of reinforcement for drug addiction: from actions to habits to compulsion. Nat Neurosci 8 (11):1481-1489. doi:10.1038/nn1579

Fleming MF, Barry KL, MacDonald R (1991) The alcohol use disorder identification test (AUDIT) in a college sample. Int J Addict 26:1173-1185. doi:10.3109/10826089109062153

Fromme K, D'Amico EJ (2000) Measuring adolescent alcohol outcome expectancies. Psychol Addict Behav 14(2):206-212. doi:10.1037//0893-164X.14.2.206

Fromme K, Stroot EA, Kaplan D (1993) Comprehensive effects of alcohol: development and psychometric assessment of a new expectancy questionnaire. Psychol Assess 5:19-26. doi:10.1037/10403590.5.1.19

Hingson R, Heeren T, Winter M, Wechsler H (2005) Magnitude of alcohol-related mortality and morbidity among U.S. college students ages 18-24: changes from 1998 to 2001. Ann Rev Public Health 26:259-279. doi:10.1146/annurev.publhealth.26.021304.144652

Hobbs M, Remington B, Glautier S (2005) Dissociation of wanting and liking for alcohol in humans: a test of the incentive-sensitization theory. Psychopharmacol (Berl) 178:493-499. doi:10.1007/ s00213-004-2026-0

Hursh SR, Silberberg A (2008) Economic demand and essential value. Psychol Rev 115:186-198. doi:10.1037/0033-295X.115.1.186

Jacobs EA, Bickel WK (1999) Modeling drug consumption in the clinic via simulation procedures: demand for heroin and cigarettes in opioid-dependent outpatients. Exp Clin Psychopharmacol 7 (4):412-426. doi:10.1037/1064-1297.7.4.412

Jajodia A, Earleywine M (2003) Measuring alcohol expectancies with the implicit association task. Psychol Addict Behav 17:126-133. doi:10.1037/0893-164X.17.2.126

Jones BT, Corbin W, Fromme K (2001) A review of expectancy theory and alcohol consumption. Addiction 96(1):57-72. doi:10.1046/j.1360-0443.2001.961575.x

Kilbey MM, Downey K, Breslau N (1998) Predicting the emergence and persistence of alcohol dependence in young adults: the role of expectancy and other risk factors. Exp Clin Psychopharmacol 6 (2):1-8. doi:10.1037/1064-1297.6.2.149

Knight JR, Wechsler H, Kuo M, Seibring M, Weitzman ER, Schuckit M (2002). Alcohol abuse and dependence among U.S. college students. J Stud Alcohol 63:263-270. Retrieved from http://www .jsad.com

Knop J, Penick EC, Jensen P, Nickel EJ, Gabrielli W, Mednick SA, Schulsinger F (2003) Risk factors that predicted problem drinking in Danish men at age thirty. J Stud Alcohol 64:745-755. Retrieved from http://www.jsad.com

Lambert NM, McLeod M, Schenk S (2006) Subjective responses to initial experience with cocaine: an exploration of the incentive-sensitization theory of drug abuse. Addiction 101:713-725. doi:10.1111/ j.1360-0443.2006.01408.x

Leigh BC, Stacy AW (1993) Alcohol outcome expectancies: scale construction and predictive utility in higher order confirmatory models. Psychol Assess 5(2):216-229. doi:10.1037/1040-3590.5.2.216

Lewis MA, Lindgren KP, Fossos N, Neighbors C, Oster-Aaland L (2009) Examining the relationship between typical drinking behavior and 21st birthday drinking behavior among college students: implications for event-specific prevention. Addiction 104(5):760-767. doi:10.1111/j.1360-0443.2009 .02518.x

MacCallum RC, Austin JT (2000) Applications of structural equation modeling in psychological research. Ann Rev Psychol 51:201-226. doi:10.1146/annurev.psyc.51.1.201 
MacKillop J, Murphy JG (2007) A behavioral economic measure of demand for alcohol predicts brief intervention outcomes. Drug Alcohol Depend 89:227-233. doi:j.drugalcdep.2007.01.002/j.drugalcdep .2007 .01 .002

McCarthy DM, Thompsen DM (2006) Implicit and explicit measures of alcohol and smoking cognitions. Psychol Addict Behav 20:436-444. doi:10.1037/0893-164X.20.4.436

Murphy JG, MacKillop J (2006) Relative reinforcing efficacy of alcohol among college student drinkers. Exp Clin Psychopharmacol 14:219-227. doi:10.1037/1064-1297.14.2.219

Murphy JG, MacKillop J, Skidmore JR, Pederson AA (2009) Reliability and validity of a demand curve measure of alcohol reinforcement. Exp Clin Psychopharmacol 17:396-404. doi:10.1037/ a0017684

Muthén B, Muthén L (1998-2010) Mplus user's guide (6th ed.). Muthén \& Muthén, Los Angeles, CA

Ostafin BD, Marlatt GA, Troop-Gordon W (2010) Testing the incentive-sensitization theory of addiction with at-risk drinkers: wanting, liking, and alcohol consumption. Psychol Addict Behav 24:157-162. doi:10.1037/a0017897

Ozkaragoz T, Noble EP (2000) Extraversion interaction between the D2 dopamine receptor polymorphisms and parental alcoholism. Alcohol 22:139-146. doi:j.drugalcdep.2007.01.002/S0741-8329 (00)00112-9

Palafi TP, Wood MD (2001) Positive alcohol expectancies and drinking behavior: the influence of expectancy strength and memory accessibility. Psychol Addict Behav 15:60-67. doi:10.1037//0893164X.15.1.60

Perkins HW (2002) Surveying the damage: a review of research on consequences of alcohol misuse in college populations. J Stud Alcohol 63:91-101. Retrieved from http://www.jsad.com

Puttemans V, Wenderoth N, Swinnen SP (2005) Changes in brain activation during the acquisition of a multifrequency bimanual coordination task: from the cognitive stage to advanced levels of automaticity. J Neurosci 25(17):4270-4278. doi:10.1523/JNEUROSCI.3866-04.2005

Reich RR, Below MC, Goldman MS (2010) Explicit and implicit measures of expectancy and related alcohol cognitions: a metaanalytic comparison. Psychol Addict Behav 24(1):13-25. doi:10.1037/ a0016556

Robinson TE, Berridge KC (1993) The neural basis of drug craving: an incentive-sensitization theory of addiction. Brain Res Rev 18:247-291. doi:j.drugalcdep.2007.01.002/0165-0173(93)90013-P

Robinson TE, Berridge KC (2001) Incentive-sensitization and addiction. Addiction 96:103-114. doi:10 $.1046 / j .1360-0443.2001 .9611038 . x$

Saunders JB, Aasland OG, Babor TF, De La Fuente JR, Grant M (1993) Development of the alcohol use disorder identification test (AUDIT): WHO collaborative project on early detection of persons with harmful alcohol consumption: II. Addiction 88:191-804. doi:10.1111/j.1360-0443.1993.tb02093.x

Schaffer M, Jeglic EL, Stanley B (2008) The relationship between suicidal behavior, ideation, and binge drinking among college students. Arch Suicide Res 12:124-132. doi:10.1080/13811110701 857111

Schuckit MA (1998) Biological, psychological, and environmental predictors of alcoholism risk: a longitudinal study. J Stud Alcohol 59:485-494. Retrieved from http://www.jsad.com

Smith GT, Goldman M (1995) Alcohol expectancy theory and identification of high-risk adolescents. In: Boyd GM, Howard J, Zucker R (eds) Alcohol problems among adolescents. Lawrence-Erlbaum Associates, Inc, Hillsdale, NJ, pp 85-104

Smith GT, Goldman MS, Greenbaum PE, Christiansen BA (1995) Expectancy for social facilitation from drinking: the divergent paths of high-expectancy and low-expectancy adolescents. J Abnorm Psychol 104(1):32-40. doi:10.1037/0021-843X.104.1.32 
Stacy AW (1997) Memory activation and expectancy as prospective predictors of alcohol and marijuana use. J Abnorm Psychol 106 (1):61-73. doi:10.1037/0021-843X.106.1.61

Stacy AW, Widaman KF, Marlatt GA (1990) Expectancy models of alcohol use. J Pers Soc Psychol 58(5):918-928. doi:10.1037/0022-3514.58.5.918

Turrisi R, Wiersma KA, Hughes KK (2000) Binge-drinking-related consequences in college students: role of drinking beliefs and mother-teen communications. Psychol Addict Behav 14:342-355. doi:10.1037//0893-164X.14.4.342

Wechsler H, Lee JE, Kuo M, Seibring M, Nelson TF, Lee H (2002) Trends in college binge drinking during a period of increased prevention efforts: findings from 4 Harvard School of Public Health College Alcohol Study surveys: 1993-2001. J Am Coll Health 50:203-217. Retrieved from http://www .acha.org/Publications/JACH.cfm

Weinberger DA, Bartholomew K (1996) Social-emotional adjustment and patterns of alcohol use among young adults. J Pers 64:495-527. doi:10.1111/j.1467-6494.1996.tb00519.x

White HR, Labouvie EW (1989) Toward the assessment of adolescent problem drinking. J Stud Alcohol 50:30-37. Retrieved from http://www.jsad.com

Wiers RW, Stacy AW, Ames SL, Noll JA, Sayette MA, Zack M, Krank M (2002a) Implicit and explicit alcohol-related cognitions. Alc Clin Exp Res 26(1):129-137. doi:10.1111/j.1530-0277.2002.tb02441.x

Wiers RW, van Woerden N, Smulders FTY, de Jong PJ (2002b) Implicit and explicit alcohol-related cognitions in heavy and light drinkers. J Abnorm Psychol 111(4):648-658. doi:10.1037//0021843X.111.4.648

Wiers RW, van de Luitgaarden J, van den Wildenberg E, Smulders FTY (2005) Challenging implicit and explicit alcohol-related cognitions in young heavy drinkers. Addiction 100:806-819. doi:10.1111/ j.1360-0443.2005.01064.x

Willner P, James D, Morgan M (2005) Excessive alcohol consumption and dependence on amphetamine are associated with parallel increases in subjective ratings of both 'wanting' and 'liking'. Addiction 100:1487-1495. doi:10.1111/j.1360-0443.2005.01222.x 